5 - ORIGINAL ARTICLE

ISCHEMIA-REPERFUSION

\title{
Effects of vardenafil on the kidney of Wistar rats submitted to acute ischemia and reperfusion $^{1}$
}

\author{
Renato Chavasco de Sousa', Antonio Augusto Moreira Neto ${ }^{\mathrm{II}}$, Vera Luíza Capelozzi ${ }^{\mathrm{III}}$, Alexandre Muxfeldt Ab'Saber ${ }^{\mathrm{IV}}$, Olavo \\ Ribeiro Rodrigues $\mathrm{V}$
}

DOI: http://dx.doi.org/10.1590/S0102-865020150050000005

IPhD, Assistant Professor, Department of Surgery, Urology Division, Mogi das Cruzes University (UMC), Brazil. Conception, design, intellectual and scientific content of the study.

${ }^{I} \mathrm{PhD}$, Assistant Professor, Department of Surgery, Vascular Surgery Division, UMC, Mogi das Cruzes-SP, Brazil. Technical procedures, acquisition of data, critical revision.

IIIPhD, Assistant Professor, Department of Pathology. Head, Division of Pulmonary Pathology, Sao Paulo University (USP), Brazil. Analysis of data. ${ }^{\text {IV }} \mathrm{PhD}$, Assistant Professor, Department of Pathology, USP, Sao Paulo--SP, Brazil. Analysis and interpretation of data.

${ }^{\mathrm{v}} \mathrm{PhD}$, Associate Professor, Department of Surgery. Head, Division of Thoracic Surgery, UMC, Mogi das Cruzes-SP, Brazil. Conception and design of the study, critical revision.

\begin{abstract}
PURPOSE: To investigate the effect of vardenafil in kidney of rats submitted to acute ischemia and reperfusion.

METHODS: Twenty-eight rats were randomly distributed into two groups. Right nephrectomy was performed and the vardenafil group received vardenafil solution (at a concentration of $1 \mathrm{mg} / \mathrm{ml}$ in $10 \mathrm{mg} / \mathrm{kg}$ ) while the control group received $0.9 \%$ saline solution (SS) one hour prior to the ligature of the left renal pedicle. After one hour of ischemia, animals were submitted to twenty-four hours of reperfusion, followed by left nephrectomy. The kidney's histological parameters evaluated on the study included vacuolar degeneration and tubular necrosis. Apoptosis was assessed by immunohistochemistry for cleaved caspase- 3 using the point-counting and digital methods (Cytophotometry). Also, a biochemical analysis for creatinine was conducted.
\end{abstract}

RESULTS: There were statistically significant differences between groups only with regards to the vacuolar degeneration parameter and to the cleaved caspase- 3 digital method.

CONCLUSION: Vardenafil showed a protective effect on the kidney of rats subjected to acute ischemia and reperfusion in this model Key words: Ischemia. Reperfusion. Immunohistochemistry. Histology. Rats. 


\section{Introduction}

The Acute Renal Failure (ARF) caused by renal ischemia is among the most common clinical problems associated with high mortality and morbidity ${ }^{1}$ and is characterized by the abrupt decline in renal function, which lasts for variable periods, resulting in renal failure on its basic functions of excretion and maintenance of electrolyte homeostasis.

Complex pathological changes occur in different cellular systems during ischemia. Over time, these changes are increased in intensity, eventually reaching critical biochemical and structural components, resulting in cell death. However, the injury is recoverable within a period that varies among the different types of cells and thus, the affected cells can recover if oxygen and metabolic substrates are offered again, restoring blood flow.

The reperfusion syndrome is characterized by metabolic acidosis; hyperkalemia caused by the loss of intracellular potassium and increased serum creatinine. Coagulation disorders, extracellular fluid accumulation and acute pulmonary distress can result in acute renal failure ${ }^{2}$. Some changes may be fatal to the cell, such as mitochondrial calcifications, nuclear pyknosis, chromatin marginalization and rupture of cell membrane. Some of these changes result from apoptosis, which is a form of cell death destined to eliminate unwanted host cells through the activation of a series of coordinated, internally programmed events executed by a unique set of gene products.

Caspases constitute a group of essential protease for apoptosis that performs the irreversible cleavage of DNA. The caspase cascade activation can be triggered by various factors such as the presence of superoxide, a derivative of muscle ischemia ${ }^{3}$. Often, reperfusion cannot be immediately performed after the beginning of ischemia, as the period of time between the first symptoms and the emergency medical care is variable.

Vardenafil is a phosphodiesterase-5 inhibitor, preserving and increasing the levels of cGMP (cyclic guanosine monophosphate) in soft muscle of the penis and increasing the erection duration. These vasodilators and inotropic agents have protective effects on vascular structures ${ }^{4}$. The effects of several drugs on this pharmacological class have been studied, especially on renal ischemia/reperfusion.

The aim of this study is to evaluate the vardenafil effect on kidney of Wistar rats after acute ischemia and reperfusion in view of the experimental models that have been reported on the subject.

\section{Methods}

The study was approved by the Ethics Committee on Animal Experimentation and Handling (CEMEA) on 17.10.2012 in accordance with the Federal Law No. 11.794, of October 8, 2008, and Decree No. 6689 of July 15, 2009, regulating Law 11.794 .

Twenty-eight adult male Wistar rats, aged 10 months and weighing 300 grams were used for the experiment. The experiment was conducted at the Technology Research Center (NPT) of University of Mogi das Cruzes from November/2012 to September/2013.

The animals were anesthetized with zolazepam/tiletamine (Zoletil ${ }^{\circledR}$ Virbac, Sao Paulo-SP) at a dose of $20 \mathrm{mg} / \mathrm{kg}$ intramuscularly in the quadriceps in an attempt to prevent depression of cardiac and respiratory. Were considered anesthetized rats showed immobility, inability to straighten the body, and no reaction to painful stimuli.

\section{Study phases}

Animals were submitted to an orogastric tube. A 4-cm long laparotomy was performed. The renal pedicle was ligated with 7.0 propylene.

Animals were randomly distributed into two groups:

Vardenafil group - 14 animals received vardenafil solution (Levitra ${ }^{\circledR}$, Bayer) in a probe at a concentration of $1 \mathrm{mg} /$ $\mathrm{ml}$ in $10 \mathrm{mg} / \mathrm{kg}$.

Group II (Saline Group) - 14 animals received 0.9\% saline solution of $10 \mathrm{~mL} / \mathrm{kg}$. Solutions were administered one hour before ligature of renal pedicle.

\section{Timing for ischemia}

After ligation of the renal pedicle, the time of ischemia started to be measured and was proceeded by the laparotomy closure. Relaparotomy was performed one hour after ischemia for removal of the renal pedicle ligature and subsequent laparotomy resuture.

\section{Timing for reperfusion}

Right after the removal of the pedicle ligature, the time of reperfusion started to be measured: twenty-four hours. Two animals were excluded from the earlier stages of the experiment because they died before the end of reperfusion time. Twenty-six animals were subjected to a second stage and were kept in the study. 


\section{Kidney and euthanasia}

The animals were anesthetized and the left nephrectomy was performed, followed by euthanasia.

The euthanasia method chosen was the exsanguination.

The left kidney was identified and fixed in $10 \%$ buffered formalin for paraffin embedding. One part was used for histological analysis and another in immunohistochemical analysis.

\section{Histological and immunohistochemical analysis}

Histological variables examined in the kidney included: vacuolar degeneration and necrosis (Figure 1).

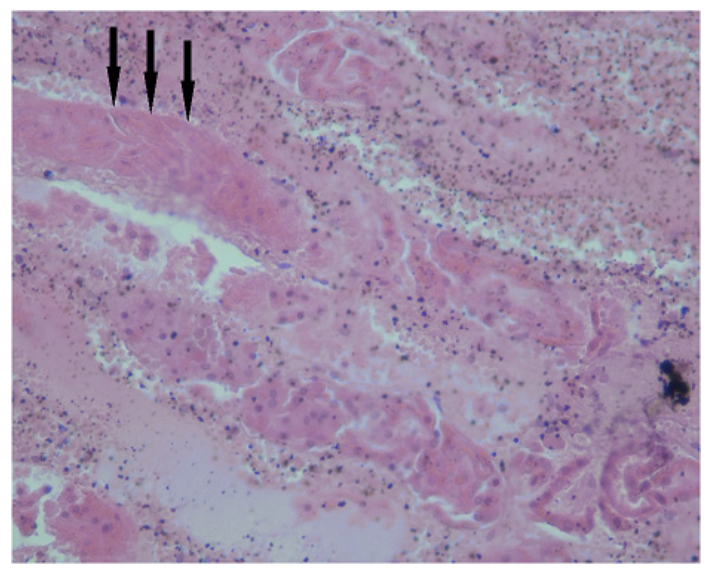

FIGURE 1 - Photomicrograph of necrosis (arrowheads) in renal cell stained with HE (x400 magnification).

Ten non-overlapping microscopic fields from each sample were analyzed, being increased on 400 times for the quantification of histological variables. The results of all variables were semiquantitatively expressed as percentage, according to the expression ratio of the changes in relation to the total observed, as follows: $0=$ absent, $1=$ less than $10 \%, 2=11 \%$ to $25 \%, 3=26 \%$ to $50 \%$, $4=$ more than $51 \%$.
The presence of apoptosis was assessed by immunohistochemistry using the cleaved caspase-3 expression performed both by the point-counting and digital methods (Cytophotometry). A microscope equipped with ocular and a grid of 50-lines and 100 points per x400 magnification was used. Ten noncoincident microscopic fields in each piece were examined in order to quantify all points that fell into the stained parts, totaling 1000 points and covering $62.500 \mu \mathrm{m}^{2}$ by field of study. Points that fell on stained areas represent the proportion of positively stained cells in the tissue areas $^{5}$.

The quantification of caspase- 3 was obtained by computer images generated by Image-Pro ${ }^{\circledR}$ Plus7.0 (Figures 2 and 3) software, numerically showing the expression of cleaved caspase- 3 . This method allowed the comparison between the point-counting and digital methods. The results of the histological and immunohistochemical analyses for the marker expression were analyzed by the nonparametric Mann-Whitney test (Wilcoxon Rank-Sum Test) for two independent samples with $\mathrm{p} \leq 0.05$. A chart of the $95 \%$ confidence interval of the average for immunohistochemical between the two groups - on twentyfour hours of reperfusion - was performed.

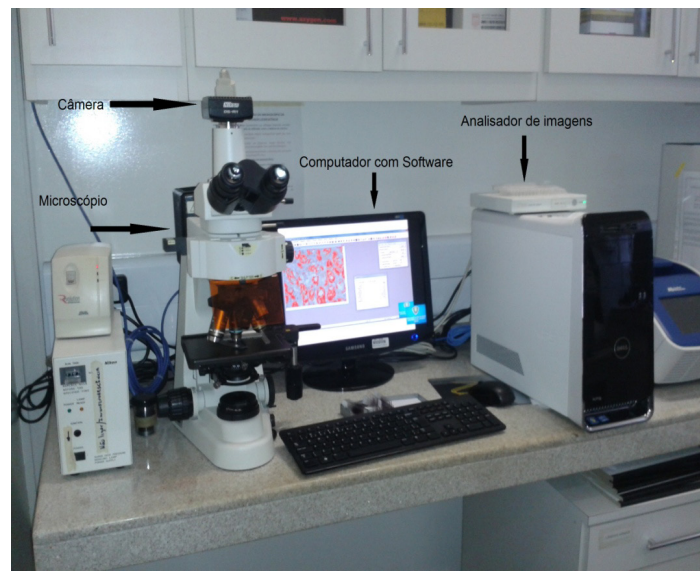

FIGURE 2 - Photograph of the image analyzer with microscope camera, image analyzer (hardware) and computer (with software) (Source: Laboratory of Pathology, USP).

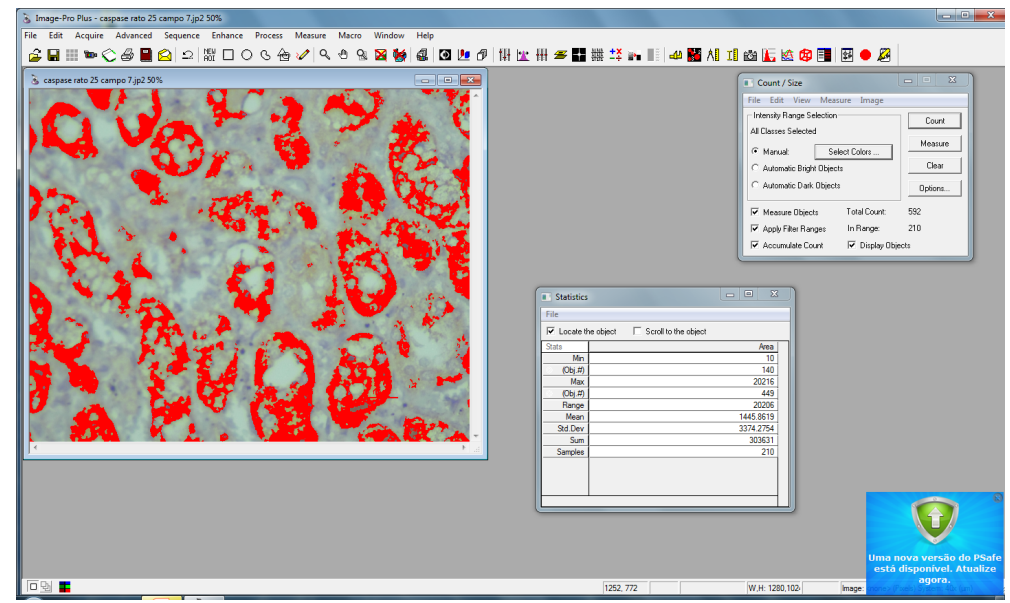

FIGURE 3 - Photograph showing on screen by the image scanning software Image-Pro Image Plus $7.0^{\circledR}$. Note that the red stained cells expressing areas stained for cleaved caspase 3 (Source: Laboratory of Pathology, USP). 


\section{Results}

Histological assessment

\section{Immunohistochemistry assessment}

The expression of cleaved caspase-3 levels is shown in Tables 1 and 2 .

The vacuolar degeneration histological change was statistically significant in the group receiving vardenafil.

TABLE 1 - Expression of cleaved caspase-3 in groups with 24 hours of reperfusion (manual method).

\begin{tabular}{|c|c|c|c|}
\hline \multicolumn{2}{|c|}{ Vardenafil Group } & \multicolumn{2}{|c|}{ Saline Solution Group } \\
\hline Number of animal & $\begin{array}{c}\text { Caspase } 3 \\
\text { (number of cells /fields) }\end{array}$ & Number of animal & $\begin{array}{c}\text { Caspase } 3 \\
\text { (number of cells /fields) }\end{array}$ \\
\hline 1 & 75 & 3 & 192 \\
\hline 2 & 120 & 7 & 212 \\
\hline 5 & 47 & 8 & 275 \\
\hline 6 & 102 & 9 & 320 \\
\hline 10 & 52 & 13 & 189 \\
\hline 12 & 172 & 17 & 305 \\
\hline 14 & 394 & 19 & 98 \\
\hline 16 & 317 & 21 & 198 \\
\hline 18 & 96 & 23 & 260 \\
\hline 20 & 243 & 25 & 272 \\
\hline 22 & 221 & 27 & 266 \\
\hline 24 & 312 & 31 & \\
\hline 26 & 312 & & 332 \\
\hline 28 & 318 & & \\
\hline Mean & 198.64 & & 243.25 \\
\hline
\end{tabular}

The comparison between the two groups through the Mann Whitney ( $\mathrm{p}$ bi) test for cleaved Caspase-3 parameter was 0.3284 .

TABLE 2 - Expression of cleaved caspase-3 in groups with 24 hours of reperfusion in cytophotometry.

\begin{tabular}{|c|c|c|c|}
\hline $\begin{array}{l}\text { Vardenafil Group } \\
\text { (number of animal) }\end{array}$ & Caspase (\%) & $\begin{array}{l}\text { Total analyzed Caspase } \\
\left(\mu^{2}\right)\end{array}$ & $\begin{array}{c}\text { Total Analyzed (10 fields) } \\
\left(\mu^{2}\right)\end{array}$ \\
\hline 2 & 10.26 & 1340.961 & 13069.243 \\
\hline 6 & 11.06 & 1447.008 & 13072.419 \\
\hline 12 & 7.63 & 997.057 & 13063.641 \\
\hline 14 & 23.25 & 3036.367 & 13059.250 \\
\hline 20 & 20.49 & 2674.886 & 13054.020 \\
\hline 22 & 15.03 & 1965.446 & 13073.298 \\
\hline 24 & 20.32 & 2657.254 & 13073.189 \\
\hline 26 & 21.94 & 2868.641 & 13070.346 \\
\hline 28 & 24.55 & 2922.399 & 11903.279 \\
\hline \multicolumn{4}{|l|}{ Saline Solution Group } \\
\hline 8 & 17.07 & 2226.023 & 13035.803 \\
\hline 9 & 20.63 & 2691.779 & 13044.154 \\
\hline 13 & 16.57 & 2163.397 & 13055.307 \\
\hline 17 & 23.20 & 3034.215 & 13078.001 \\
\hline 19 & 29.96 & 3914.426 & 13065.305 \\
\hline 21 & 30.28 & 3600.046 & 11887.363 \\
\hline 23 & 21.34 & 2791.126 & 13075.093 \\
\hline 25 & 26.58 & 3476.425 & 13077.532 \\
\hline 27 & 21.59 & 2538.969 & 13084.708 \\
\hline 31 & 27.42 & 3582.051 & 13063.232 \\
\hline Mean & & 2996.679 & 11988.609 \\
\hline Mann-Whitney & & 3096.583 & 13050.141 \\
\hline
\end{tabular}


The results showed that the total number of cells undergoing quantified apoptosis by cleaved caspase-3 was lower in kidneys of animals receiving vardenafil with 24-hours of reperfusion. These differences were not statistically significant, but the quantification of cleaved caspase- 3 by cytophotometry was statistically significant at $\mathrm{p}=0.0055$.

\section{Discussion}

The proposed model tries to reproduce a real situation to which the surgeon is often exposed, on trying to cause the least possible damage to both the physiological and renal histology when temporary renal ischemia is necessary for the surgical procedure.

Different substances have been used in experimental studies with the goal of protecting the kidney against the effects of ischemia/reperfusion ${ }^{6}$.

Among the most widely used, we find the phosphodiesterase-5 inhibitors; compounds which inhibit or antagonize the biosynthesis of that enzyme. The phosphodiesterase- 5 is frequently and widely used in the treatment of pulmonary hypertension and erectile dysfunction in men ${ }^{6-7}$.

In the literature, sildenafil citrate and sildenafil are the most commonly phosphodiesterase-5 inhibitors investigated for this purpose ${ }^{8}$. Vardenafil is a phosphodiesterase- 5 which role is of inhibiting the increase on this enzyme increase and maintain levels of cGMP (cyclic guanosine monophosphate) in the smooth muscle of the penis, increasing the duration of erection.

Experimental studies have demonstrated that inhibitors of phosphodiesterase-5 had a protective effect against ischemic injury in animal models when used in other organs. Several experiments had models which were similar to those used in the present study, when investigating the effectiveness of other drugs on ischemia-reperfusion process.

A recently published study ${ }^{5}$ using doses of $0.02 ; 0.2 ; 2$ and $20 \mu \mathrm{g} / \mathrm{kg}$ vardenafil concluded that there was a significant attenuation of the process of ischemia/reperfusion injury in the group treated with this drug when compared to the control group, with reduced levels of creatinine, histological score, sodium excretion and scintigraphic standard. However, these results were dependent on the vardenafil dose used. It is also noted that the author used an ischemia period of forty-five minutes and a reperfusion period of 4 hours and seventy-one rats.

The pathological alteration of vacuolar degeneration of tubular cells was statistically significant in the control group when compared to the vardenafil group. Necrosis was also higher in the control group, though not significant. Creatinine results were slightly higher in the vardenafil group, but not statistically significant.

The cleaved caspase- 3 expression obtained by manual and digital methods (cytophotometry) ${ }^{9}$ has been currently used. By the manual method, the expression was lower in the vardenafil group with twenty-four hours of reperfusion, but not statistically significant. This fact may suggest a trend for protection of vardenafil on the renal cell injury through 24 hours of reperfusion, and therefore, the assessment through the Cytophotometry method was statistically significant. The explanation for the imaging method having been statistically more significant than the manual method is because of its higher specificity.

\section{Conclusion}

Vardenafil showed a protective effect on kidney of rats subjected to acute ischemia and reperfusion in the model under study.

\section{References}

1. Liang X, Chen Y, Zhang L, Jiang F, Wang W, Ye Z, Liu S, Yu C, Shi W. Necroptosis, a novel form of caspase-independent cell death, contributes to renal epithelial cell damage in an ATP-depleted renal ischemia model. Mol Med Rep. 2014 Aug;10(2):719-24. doi: 10.3892/mmr.2234.

2. Blaisdell FW. The reperfusion syndrome. Microcirc Endothelium Lymphatics. 1989 Jun-Oct;5(3):127-41. PMID: 2700372.

3. Silveira M, Yoshida SB. Isquemia e reperfusão em músculo esquelético. J Vasc Br. 2004 Sep;3(4):367-78.

4. Sestic C, Florio V, Johnson EG, Kloner RA. The phosphodiesterase-5 inhibitor tadalafil reduces myocardial infarct size. Int J Impot Res. 2007 Jan-Feb;19(1):55-61.

5. Kyriazis I, Kagadis GC, Kallidonis P, Georgiopoulos I, Marazioti A, Geronasiou A, Liourdi D, Loudos G, Schinas V, Apostolopoulos D, Papadaki H, Flordellis C, Nikiforidis GC, Papapetropoulos A, Liatsikos EN. PDE5 inhibition against acute renal ischemia reperfusion injury in rats: does vardenafil offer protection? World J Urol. 2013 Jun;31(3):597-602. doi: 10.1007/s00345-012-0980-4.

6. Baldwin DD, Maynes LJ, Berger KA, Desai PJ, Zuppan CW, Zimmerman GJ, Winkielman AM, Sterling TH, Tsai CK, Ruckle HC. Laparoscopic warm renal ischemia in the solitary porcine kidney model. Urology. 2004 Sep;64(3):592-7.

7. Sawamura F, Kato M, Fujita K, Nakazawa T, Beardsworth A. Tadalafil, a long-acting inhibitor of PDE5, improves pulmonary hemodynamics and survival rate of monocrotaline-induced pulmonary artery hypertension in rats. J Pharmacol Sci. 2009 Nov;111(3):235-43.

8. Guzeloglu M, Yalcinkaya F, Atmaca S, Bagriyanik A, Oktar S, Yuksel O, Fansa I, Hazan E. The beneficial effects of tadalafil on renal ischemia-reperfusion injury in rats. Urol Int. 2011 Dec;86(2):197203. doi: 10.1159/000321927.

9. Huang Y, Cheng Y, Wu J, Li Y, Xu E, Hong Z, Li Z, Zhang W, Ding M, Gao X, Fan D, Zeng J, Wong K, Lu C, Xiao J, Yao C. cilostazol versus aspirin for secondary ischaemic stroke: randomised, double- 
Sousa RC et al.

blind, pilot study. Lancet Neurol. 2008 Jun;7(6):494-9. doi: 10.1016/ S1474-4422(08)70094-2.

\section{Correspondence:}

Renato Chavasco de Sousa

Rua Cel. Santos Cardoso, 443

08730-110 Mogi das Cruzes - SP Brasil

Tel.: (55 11)4724-8000

rcsdoctor@uol.com.br

Received: Jan 16, 2015

Review: Mar 19, 2015

Accepted: Apr 18, 2015

Conflict of interest: none

Financial source: none

${ }^{1}$ Research performed at Center for Technological Research (NPT), Mogi das Cruzes University (UMC), Brazil. Part of PhD degree thesis, Postgraduate Program in Biomedical Engineering, UMCs. Tutor: Olavo Ribeiro Rodrigues. 